\title{
Kadın Futbolcularda Tekrarlı Sprint, Çoklu Sıçrama ve Wingate Testleri Arasındaki İlişskinin Belirlenmesi*
}

\author{
Halit HARMANCI ${ }^{* *}$ \\ M.Barış KARAVELIOĞLU ${ }^{* * *}$ \\ Gizem BAŞKAYA ${ }^{* * * *}$ \\ Mustafa Said ERZEYBEK ${ }^{* * * *}$
}

\section{Öz}

Bu çalışmanın amacı kadın futbolcularda wingate, tekrarlı sprint (RAST) ve 30 sn çoklu sıçrama testleri arasındaki ilişkinin belirlenmesidir. Çalışmaya yaş, boy ve vücut ağırlığı ortalamaları $19.57 \pm 1.28$ yıl, $165.78 \pm 5.04 \mathrm{~cm}$ ve $58.14 \pm 4.80 \mathrm{~kg}$ olan 14 kadın futbolcu gönüllü olarak katılmıştır. Çalışmaya katılan sporcuların, wingate, $6 \times 35 \mathrm{~m}$ tekrarlı sprint (RAST test) ve 30 sn çoklu sıçrama testlerine ait anaerobik performans değerleri rastgele örneklem yöntemi ile en az 48 saat arayla belirlenmiştir. Katılımcıların test öncesi, testin hemen sonrası ve testin 5., 7. ve 9. dakikası sonrası kalp atım hızları ve kan laktat değerleri tespit edilmiştir. Wingate, $6 \times 35 \mathrm{~m}$ tekrarlı sprint (RAST test) ve $30 \mathrm{sn}$ çoklu sıçrama testlerine ait anaerobik performans değerleri arasındaki ilişkiyi belirlemede Pearson kolerasyon katsayısı, ölçümler arasındaki tutarlılık Bland-Altman Analiziyle değerlendirilmiştir. Çalışmaya katılan sporcuların wingate, $6 \times 35 \mathrm{~m}$ tekrarlı sprint (RAST test) ve 30 sn çoklu sıçrama testi öncesi ve sonrasındaki kalp atım hızları ve kan laktat değerleri arasında farkı belirlemede çok boyutlu varyasyon analizi (MANOVA) testi kullanılmıştır.

Çalışmaya katılan sporcuların wingate testinden elde edilen güç değerleri (absolüt pik güç, relatif pik güç, absolüt ortalama güç ve relatif ortalama güç) ile $6 \times 35 \mathrm{~m}$ tekrarlı sprint (RAST test) testinden elde edilen güç değerleri arasında anlamlı ilişkiler tespit edilmiştir $(R 1=0.98, R 2=0.98, R 3=0.96$ ve $R 4=0.93$, $\mathrm{p}<0.01$ ). Wingate testinden elde edilen güç değerleri ile 30 sn çoklu sıçrama testinden elde edilen güç değerleri ( $\mathrm{R} 1=0.49, \mathrm{R} 2=0.33, \mathrm{R} 3=0.38$ ve $\mathrm{R} 4=0.24, \mathrm{p}>0.05)$. $6 \times 35 \mathrm{~m}$ tekrarlı sprint (RAST test) testinden elde edilen güç değerleri ile 30 sn çoklu sıçrama testinden elde edilen güç değerleri arasında $(\mathrm{R} 1=0.43, \mathrm{R} 2=0.27, \mathrm{R} 3=0.43$ ve $\mathrm{R} 4=0.31, \mathrm{p}>0.05)$ ise anlamlı ilişkiler tespit edilememiştir. Wingate testinden elde edilen güç değerleri ile $6 \times 35 \mathrm{~m}$ tekrarlı sprint (RAST test) testinden elde edilen güç

\footnotetext{
* Bu araştırma, 22-26 Mayıs 2015 tarihleri arasında 4. Uluslararası Bilim Kültür ve Spor Kongresi’nde poster bildiri olarak sunulmuştur

** Yrd.Doç.Dr., Dumlupınar Üniversitesi, Beden Eğitimi ve Spor Yüksekokulu, halitharmanci@hotmail.com

*** Yrd.Doç.Dr., Dumlupınar Üniversitesi, Beden Eğitimi ve Spor Yüksekokulu, karavelioglu01@hotmail.com

${ }_{* * * *}$ Doktora Öğrencisi, Dumlupınar Üniversitesi, Beden Eğitimi ve Spor Yüksekokulu, bskygzm@gmail.com

***** Yrd.Doç.Dr., Dumlupınar Üniversitesi, Beden Eğitimi ve Spor Yüksekokulu, msaid.erzeybek@dpu.edu.tr
} 
değerleri arasında anlamlı yüksek ilişkiler olmasına rağmen, Bland-Altman tutarlılık gösteriminde iki ölçüm arasındaki farklılığın \%95 güven aralığını aştığı tespit edilmiştir. Yapılan Multivariate Analysis of Variance (MANOVA) testi sonrası çalışmaya katılan sporcuların wingate, $6 \times 35 \mathrm{~m}$ tekrarlı sprint (RAST test) ve 30 sn çoklu sıçrama testinin hemen sonrası ve toparlanmanın 5.,7 ve 9. dakikası sonrası kalp atım hızları ve kan laktat değerleri arasında anlamlı farka rastlanmıştır.

Anahtar kelimeler: Wingate testi, tekrarlı sprint testi, çoklu sıçrama testi

\title{
The Relationship Between Wingate Test, Running-Based Anaerobic Sprint Test (rast) and 30 s. Repetitive Vertical Jumping Test in Female Soccer Players
}

\begin{abstract}
The purpose of this study was to determine relationship between wingate test, Running-based Anaerobic Sprint Test (RAST) and 30 s. repetitive vertical jumping test in female soccer players. 14 female soccer players whose age, height and weight were $19.57 \pm 1.28$ years, $165.78 \pm 5.04 \mathrm{~cm}$ and $58.14 \pm 4.80 \mathrm{~kg}$. volunteered to participate in this investigation. The athletes who participated in this study were performed $6 \times 35$ m RAST, $30 \mathrm{~s}$. repetitive vertical jump and wingate test in a random order at least 48 hours apart. Heart rate and blood lactate values of the participants were determined at rest, immediately after the tests and 5th, 7th and 9th minutes of the tests.

Pearson correlation coefficients were used to define correlation between peak and mean power of the $6 \times 35 \mathrm{~m}$ RAST, $30 \mathrm{~s}$. repetitive vertical jump and wingate test. The consistency between power measurements were determined by the Bland-Altman analysis. Multivariate Analysis of Variance (MANOVA) was used to determine whether there are any differences in heart rate and blood lactate levels at rest and after the wingate, $6 \times 35 \mathrm{~m}$ RAST and $30 \mathrm{~s}$. repetitive vertical jumping tests. There are significant correlations found between wingate and $6 \times 35$ m RAST tests in absolute anaerobic power, relative anaerobic power, absolute anaerobic capacity and relative anaerobic capacity results $(\mathrm{R} 1=0.98$, $\mathrm{R} 2=0.98, \mathrm{R} 3=0.96$ and $\mathrm{R} 4=0.93, \mathrm{p}<0.01$ ). There was no significant correlations found between wingate and 30 s. repetitive vertical jump tests $(R 1=0.49, R 2=0.33, R 3=0.38$ and $R 4=0.24, p>0.05)$ and also between RAST and $30 \mathrm{~s}$. repetitive vertical jump tests $(\mathrm{R} 1=0.43, \mathrm{R} 2=0.27, \mathrm{R} 3=0.43$ and $\mathrm{R} 4=0.31$, $\mathrm{p}>0.05)$ in absolute anaerobic power, relative anaerobic power, absolute anaerobic capacity and relative anaerobic capacity results. Although there was a high correlation between Wingate and 6x35 m RAST tests, Bland-Altman consistency analysis showed that the differences between the two measurements were found to exceed the 95\% confidence interval. Multivariate Analysis of Variance (MANOVA) indicated that there were significant differences in heart rate and blood lactate concentrations following $6 \times 35 \mathrm{~m}$ RAST, 30 s. repetitive vertical jump and wingate test $(\mathrm{p}<0,05)$.
\end{abstract}

Keywords: Wingate test, running-based anaerobic sprint test and repetitive jumping test 


\section{GíRiş}

Anaerobik yetenek, adenozin trifosfat resentez hızının çok önemli bir değişken olduğu maksimum ve yoğun güç gerektiren yarışmalarda performans için önemlidir (Queiroga ve ark., 2013, Nummela ve ark., 1996). Anaerobik performansını değerlendirmek için bisiklet ergometresinden koşu testine kadar geniş sayıda test protokolü mevcuttur (Queiroga ve ark., 2013). Wingate testi, sıçrama testleri ve maksimal anaerobik koşu testleri pahalı olmayan ve yaygın olarak kullanılan testlerdir (Kaminagakura ve ark., 2012). Bir değerlendirme işleminin güvenirliği ve tekrar edilebilirliği bilimsel olarak kabul görmede oldukça önemlidir (Zagatto ve ark., 2009, Vandewalle ve ark., 1987). Anaerobik gücün ölçümü için birçok test yöntemi kullanılsa da bu testlerin güvenilirlik değerleri farklılıklar göstermektedir (Kaminagakura ve ark., 2012).

Anaerobik kapasiteyi belirlemede en yaygın kullanılan testlerden biri Wingate anaerobik güç testidir (Adamczyk, 2011, Jastrzebski, 1995). Anaerobik güç ve kapasitenin değerlendirilmesi için iyi bir yöntem olarak bilimsel kabul gördüğü için wingate bisiklet testi, farklı sportif özellikteki anaerobik değerlendirme testlerinin geçerliliğini doğrulamada standart yöntem olarak kullanılmaktadır (Zagatto ve ark., 2009, Nummela ve ark.,1996). Değişik çalışmalarda wingate testinden ölçülen parametrelerle anaerobik kapasite arasında bir ilişkinin olduğu ifade edilmiştir (Zagatto ve ark., 2011, Minahan ve ark., 2007, Smith ve Hill, 1991). Green ve Dawson (1995) ortalama güç, pik laktat ve yorgunluk indeksinin glikolitik sistemi tahmin edebileceğini ve anaerobik kapasite oranını temsil edebileceğini ifade etmişlerdir. Ayrıca sporcuların anaerobik antrenman durumunu değerlendirmede kullanılmakta ve koşularda kısa mesafeli performansın iyi bir göstergesi olarak değerlendirilmektedir (Zagatto ve ark., 2011, Meckel ve ark., 1995, Tharp ve ark., 1985). Uygulamada wingate testinin kullanımı düzgün donanıma sahip laboratuar cihazlarına erişimi gerektirmesine rağmen, daha karmaşık bilimsel doğrulanmış sonuçlar elde edilmesini sağlar (Adamczyk, 2011).

RAST testi; pik güç, ortalama güç ve yorgunluk indeksi değişkenlerini ölçen, anaerobik güç ve kapasiteyi değerlerini test etmede kullanılan wingate testinden uyarlanmıștır (Zacharogiannis ve ark., 2004). Rast testi 10 saniye dinlenme aralıkları ile 6 tane $35 \mathrm{~m}$ maksimal sprintleri içerir (Kalva-Filho ve ark., 2013, Zagatto ve ark., 2009). Vücut ağırlığının ve koşu zamanının belirlenmesiyle, her sprintte eforun gücünü belirlemek mümkündür (Anaerobik Güç = (Vücut Ağırlığ $\mathrm{X} \mathrm{mesafe}{ }^{2}$ ) / zaman ${ }^{3}$ ). Kolay uygulanan bir yöntem olduğu için pratik uygulamalarda oldukça caziptir. Ancak RAST testinin test-tekrar test güvenirliği ve geçerliliği konusunda hala daha fazla araştırmaya ihtiyacı vardır (Zagatto ve ark., 2009).

Dikey sıçrama rekabet gücü en yüksek sporlarda kullanılan temel bir beceridir (Baljinder ve ark., 2014). Antrenman rejimlerinin birçoğunda amaç ilgili sporda atletin performansını artırmak için dikey sıçrama yeteneğini en üst düzeye çıkarmaya çalışmaktır (Baljinder ve ark., 2014, Reiser ve ark., 2006). Sıçrama ve çabukluk gerektiren sporlarda, kassal kuvvet ve güce gereksinim vardır (Baljinder ve ark., 2014, Semler, 2011). Bosco testinin benzersizliği nispeten uzun süre boyunca tekrarlanan alt ekstremite hareketlerinde uzuma kısalma döngüsünün büyük oranda kullanılmasında yatmaktadır (Sands ve ark., 2004). Ancak, Bosco testi henüz wingate testi gibi aynı derecede bilimsel kabul görülebilirlik düzeyine ulaşamamıştır (Changela ve Bhatt ,2012, Sands ve ark., 2004). Wingate testi 
tüm popülasyona ait bireylerde diğer anaerobik performans testlerine oranla daha yoğun bir şekilde uygulanmış ve oldukça güvenilir ve geçerli olarak bulunmuştur (Bar-Or, 1996). Bosco testi; uzama kısalma döngüsünü içeren sporlarda ilgi görmesinden dolayı, farklı antrenman geçmişine sahip katılımcılarda çok çeşitli çerçevede detaylı bir şekilde değerlendirilmesi yararlı olacaktır (Sands ve ark., 2004). Bu yüzden bu çalışmanın amacı kadın futbolcularda wingate, tekrarlı sprint (RAST) ve 30 sn. çoklu sıçrama testleri arasındaki ilişkinin belirlenmesidir.

\section{YÖNTEM}

\section{Çalışma Grubu}

Çalışmaya yaş, boy ve vücut ağırlığı ortalamaları $19.57 \pm 1.28$ yıl, $165.78 \pm 5.04 \mathrm{~cm}$ ve $58.14 \pm 4.80$ kg. olan, en az 4 yıldır spor yapan,14 kadın futbolcu gönüllü olarak katılmıştır.

\section{Ölçüm Araçları}

\section{Boy Ölçümleri}

Katılımcıların boy uzunlukları anatomik pozisyonda, çıplak ayakla ve baş frontal düzlemde olacak şekilde $1 \mathrm{~mm}$ hassasiyetle duvara monte edilmiş stadiometre ile (Holtain Ltd. U.K.) ölçülmüştür.

\section{Vücut Ağırlığı Ölçümleri}

Katılımcıların vücut ağırlığı̈ ölçümleri standart spor kıyafetleri (şort ve t-shirt) ve çıplak ayakla $0.1 \mathrm{~kg}$ hassasiyetle baskülde (Tanita TBF 401 A Japan) ölçülmüştür.

\section{Kalp Atım Hızı Ölçümleri}

Katılımcıların kalp atım hızları 5 sn aralıklarla telemetrik monitör aracılığıyla ölçülmüştür (Polar RS800CX Heart Rate Monitor, Finland). Sistem, elastik bir band ile deneğin üzerine sabitlenen verici ünite ve deneğin koluna takılan telemetrik monitörden oluşmaktadır.

\section{Kan Laktat Ölçümleri}

Çalışmaya katılan sporcuların kan laktat değerleri Eco Twenty Care Diagnostica laktat analizörü ile belirlenmiştir. Sporcuların laktat ölçümleri; parmak ucu lanset yardımıyla delinerek açığa çıkan kan örneği 20 ml’lik kapiler tüp içerisine alınmıştır. Kapiler tüplere alınan kan örnekleri analiz için içinde parçalayıcı ajanlar bulunan 2.0 ml'lik kapaklı plastik numune kabı içerisine bırakılarak kapağı kapatılmıştır. Plastik numune kabı elle çalkanıp kapiler tüp içindeki kanın plastik kap içerisindeki solüsyona difüze olması sağlanmıştır. Plastik numune kabı içerisinde bulunan numuneler, laktat analizörünün tepsisinde bulunan numaralandırılmış boşluklara sırayla yerleştirilmiştir. Cihazın ölçüm yapabilmesi için üretici firmanın belirttiği kalibrasyon süreçlerinden geçmesi ön şarttır. Cihazın kalibrasyonu; üretici firmadan sağlanan 2.0 ml'lik tüpler

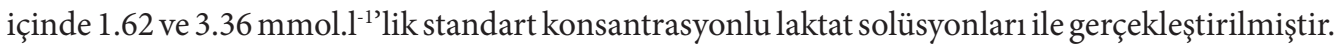




\section{Wingate Testi}

Anaerobik güç ve kapasite bilgisayar bağlantılı bisiklet ergometresinde (Monark 894E, Peak Bike, Sweden) wingate Testi ile belirlenmiştir. Deneklere test hakkında bilgi verildikten sonra teste başlamadan önce, bisiklet 60-70 W iş yükünde, 60-70 devir /dk pedal hızında 5 dakika ısınma protokolü uygulanmıştır. Isınma protokolü sonrasında 5 dakikalık pasif dinlenme verilmiştir. Isınma sonrasında her denek için sele ve gidon ayarı yapılıp, ayaklar klipsler yardımıyla pedala sabitlenmiştir. Her denek için ilk testin başlamasından önce elde edilen vücut ağırlığının \% 7,5’ine karşılık gelen ağırlık test sırasında uygulanacak dış direnç olarak bisiklet ergometresinin kefesine yerleştirildikten sonra test başlatılmıştır. Deneklerin dirençsiz olarak mümkün olan en kısa zamanda en yüksek pedal hızına ulaşmaları istenmiştir. Pedal hızı 150 devir/dk’ye ulaştığında kefe otomatik olarak inmiş ve test başlamıştır. Denekler dış dirence karşı 30 saniye boyunca en yüksek hızda pedal çevirmişlerdir. Denekler test boyunca sözel olarak teşvik edilmişlerdir. Test sırasındaki güç parametrelerine ait bilgi RS 232 bağlantısıyla bilgisayardaki yazılım programına aktarılmıştır. Tüm güç parametreleri yazılım programı tarafından hesaplanmıştır.

\section{Çoklu Sıçrama Testi}

Deneklerin 30 sn çoklu sıçrama gücünün elde edildiği ölçümler Newtest Powertimer 300-series sıçrama platformu üzerinde gerçekleştirilmiştir. Çalışmaya katılan deneklerden 30 saniye boyunca platform üzerinde mümkün olduğu kadar en yükseğe sıçramaları istenmiştir. Çoklu sıçramaya ait güç parametreleri yazılım programı tarafından otomatik olarak hesaplanmıştır.

\section{Tekrarlı Sprint Testi (RAST test)}

Çalışmaya katılan sporcuların 6x35 m tekrarlı sprint testleri bilgisayar bağlantılı fotosel sistemi (Newtest Powertimer 300-series) ile belirlenmiştir. Tekrarlı sprint testine ait güç değerleri yazılım programı tarafından otomatik hesaplanmıştır.

\section{Verilerin Toplanması}

Çalışmaya katılan katılımcıların testlere başlamadan önce çalışmanın amacı ve testler hakkında bilgi verilmiştir. Çalışmaya katılan sporcuların wingate, 6 X35 m tekrarlı sprint (RAST test) ve 30 sn çoklu sıçrama testlerine ait anaerobik performans değerleri rastgele örneklem yöntemi ile en az 48 saat arayla toplam 6 günde belirlenmiştir. Katılımcıların test öncesi ve testin 5.,7. ve 9. dakikası sonrasına ait kalp atım hızları ve kan laktat değerleri tespit edilerek ölçüm formuna kaydedilmiştir. Katılımcıların pasif dinlenmeleri testlerin tamamlanmasından hemen sonra sandalye üzerinde gerçekleştirilmiştir. 


\section{İstatistiksel Analiz}

Çalışmaya katılan sporcuların wingate, 6 X35 m tekrarlı sprint (RAST test) ve 30 sn çoklu sıçrama testlerine ait anaerobik performans değerleri arasındaki ilişkiyi belirlemede Pearson kolerasyon katsayısı, ölçümler arasındaki tutarlılık Bland-Altman Analiziyle değerlendirilmiştir. Çalışmaya katılan sporcuların wingate, 6X35 m tekrarlı sprint (RAST test) ve 30 sn çoklu sıçrama testi öncesi ve sonrasındaki kalp atım hızları ve kan laktat değerleri arasında farkı belirlemede Multivariate Analysis of Variance (MANOVA) testi kullanılmıștır.

\section{BULGULAR}

Çalışmada yer alan sporcuların wingate, 6x35 m tekrarlı sprint (RAST test) ve 30 sn çoklu sıçrama testlerine ait anaerobik güç ve kapasite değerleri Tablo1'de gösterilmiştir.

Tablo I. Kadın Futbolcuların Wingate, $6 \times 35 \mathrm{~m}$ Tekrarlı Sprint (RAST test) ve 30 sn Çoklu Sıçrama Testlerine ait Anaerobik Güç ve Kapasite Değerleri

\begin{tabular}{lccc}
\hline Wingate Testi & $\begin{array}{c}\text { Tekrarlı Sprint Testi } \\
\text { (RAST) }\end{array}$ & $\begin{array}{c}\text { 30 sn. Çoklu Siçrama } \\
\text { Testi }\end{array}$ \\
\hline & $\begin{array}{c}\text { Ortalama } \pm \text { Ss } \\
(\mathbf{n}=\mathbf{1 4})\end{array}$ & $\begin{array}{c}\text { Ortalama } \pm \text { Ss } \\
(\mathbf{n}=\mathbf{1 4})\end{array}$ & $\begin{array}{c}\text { Ortalama } \pm \text { Ss } \\
(\mathbf{n}=\mathbf{1 4})\end{array}$ \\
Pik Güç (watt) & $462.35 \pm 40.59$ & $455.50 \pm 45.20$ & $2114.47 \pm 268.48$ \\
Pik Güç/kg (watt/kg) & $7.98 \pm 0.76$ & $7.86 \pm 0.82$ & $36.38 \pm 3.86$ \\
Ortalama Güç (watt) & $356.03 \pm 34.41$ & $420.08 \pm 47.39$ & $1950.18 \pm 249.34$ \\
Ortalama Güç/kg (watt/kg) & $6.15 \pm 0.71$ & $7.18 \pm 1.02$ & $33.53 \pm 3.25$ \\
\hline
\end{tabular}

Çalışmaya katılan sporcuların wingate testinden elde edilen güç değerleri (absolüt pik güç, relatif pik güç, absolüt ortalama güç ve relatif ortalama güç) ile $6 \times 35 \mathrm{~m}$ tekrarlı sprint (RAST test) testinden elde edilen güç değerleri arasında anlamlı ilişkiler tespit edilmiştir $\left(\mathrm{R}_{1}=0.98, \mathrm{R}_{2}=0.98, \mathrm{R}_{3}=0.96\right.$ ve $\mathrm{R}_{4}=0.93$, $\mathrm{p}<0.01$ ). Wingate testinden elde edilen güç değerleri (absolüt pik güç, relatif pik güç, absolüt ortalama güç ve relatif ortalama güç) ile 30 sn çoklu sıçrama testinden elde edilen güç değerleri $\left(\mathrm{R}_{1}=0.49\right.$, $\mathrm{R}_{2}=0.33, \mathrm{R}_{3}=0.38$ ve $\mathrm{R}_{4}=0.24, \mathrm{p}>0.05$ ). $6 \mathrm{X} 35 \mathrm{~m}$ tekrarlı sprint (RAST test) testinden elde edilen güç değerleri ile 30 sn çoklu sıçrama testinden elde edilen güç değerleri arasında $\left(R_{1}=0.43, R_{2}=0.27\right.$, $\mathrm{R}_{3}=0.43$ ve $\mathrm{R}_{4}=0.31, \mathrm{p}>0.05$ ) ise anlamlı ilişkiler tespit edilememiștir (Tablo 2). 
Tablo 2. Kadın Futbolcuların Wingate, $6 \times 35$ m Tekrarlı Sprint (RAST test) ve 30 sn Çoklu Sıçrama Testlerine Ait Anaerobik Performans Değerleri Arasındaki İlişki

\begin{tabular}{|c|c|c|c|c|c|c|c|c|c|c|c|c|}
\hline & $\begin{array}{c}\text { Rast } \\
\text { Pik Güç }\end{array}$ & $\begin{array}{c}\text { Rast } \\
\text { Pik Güç } \\
\text { / kg }\end{array}$ & $\begin{array}{l}\text { Rast } \\
\text { Ortalama } \\
\text { Güç }\end{array}$ & $\begin{array}{c}\text { Rast } \\
\text { Ortalama } \\
\text { Güç / kg }\end{array}$ & $\begin{array}{c}\text { Çoklu } \\
\text { Sıçrama } \\
\text { Pik Gücü }\end{array}$ & $\begin{array}{c}\text { Çoklu } \\
\text { Sıçrama } \\
\text { Pik Gücü } \\
/ \mathrm{kg}\end{array}$ & $\begin{array}{l}\text { Çoklu } \\
\text { Sıçrama } \\
\text { Ortlama } \\
\text { Gücü }\end{array}$ & \begin{tabular}{c|} 
Çoklu \\
Sıçrama \\
Ortlama \\
Gücü \\
$/ \mathrm{kg}$ \\
\end{tabular} & $\begin{array}{l}\text { Wingate } \\
\text { Pik Güç }\end{array}$ & $\begin{array}{c}\text { Wingate } \\
\text { Pik Güç } \\
\text { / kg }\end{array}$ & $\begin{array}{c}\text { Wingate } \\
\text { Ortalama } \\
\text { Güç }\end{array}$ & $\begin{array}{c}\text { Wingate } \\
\text { Ortalama } \\
\text { Güç } \\
/ \mathrm{kg}\end{array}$ \\
\hline Rast Pik Güç & 1 & & & & & & & & & & & \\
\hline Rast Pik Güç / kg & .661 & 1 & & & & & & & & & & \\
\hline Rast Ortalama Güç & $949^{* 4}$ &, $753^{4}$ & 1 & & & & & & & & & \\
\hline Rast Ortalama Güç / kg & $.551^{\dagger}$ & $940^{\circ}$ & $709^{*}$ & 1 & & & & & & & & \\
\hline Çoklu Sıçrama Pik Gücü & ,428 &,- 082 & ,341 & -126 & 1 & & & & & & & \\
\hline Çoklu Sıçrama Pik Gücü / kg &, 222 & ,273 & ,255 & ,261 & $.744^{* 1+}$ & 1 & & & & & & \\
\hline Çoklu Sıçrama Ortlama Gücü & $.551^{\dagger}$ &,- 021 &, 432 &,- 096 &, 956 & $628^{\circ}$ & 1 & & & & & \\
\hline Coklu Sıçrama Ortlama Gücü / kg & .412 & ,367 &, 400 & .313 & $757^{4+4}$ & $924^{4 \prime}$ & $754^{* 4}$ & 1 & & & & \\
\hline Wingate Pik Güç & $976^{* *}$ & $.615^{\circ}$ & $928^{4 *}$ &, 504 &, 493 & ,282 & .591 & ,442 & 1 & & & \\
\hline Wingate Pik Güç / kg & $.586^{\circ}$ & $976^{4 \prime}$ & $699^{\prime \prime}$ & $925^{\prime \prime}$ &,- 077 & ,331 &,- 050 & 382 & $584^{4}$ & 1 & & \\
\hline Wingate Ortalama Güç & 901 & $.703^{4}$ & $.959^{*}$ & $663^{\prime \prime}$ &, 319 & ,220 & 382 & ,325 & 901 & $.668^{4}$ & 1 & \\
\hline Wingate Ortalama Güç / kg & ,488 & $.923^{4}$ & $.666^{t \prime}$ & $932^{\prime \prime}$ & |181 & ,234 & 182 & ,241 & ,469 & $.937^{\prime \prime}$ & $.698^{4+}$ & \\
\hline
\end{tabular}

Wingate testinden elde edilen güç değerleri ile 6X35 m tekrarlı sprint (RAST test) testinden elde edilen güç değerleri arasında anlamlı yüksek ilişkiler olmasına rağmen, Bland-Altman tutarlılık gösteriminde iki ölçüm arasındaki farklılığın \% 95 güven aralığını aştığı tespit edilmiştir (Grafik 1).

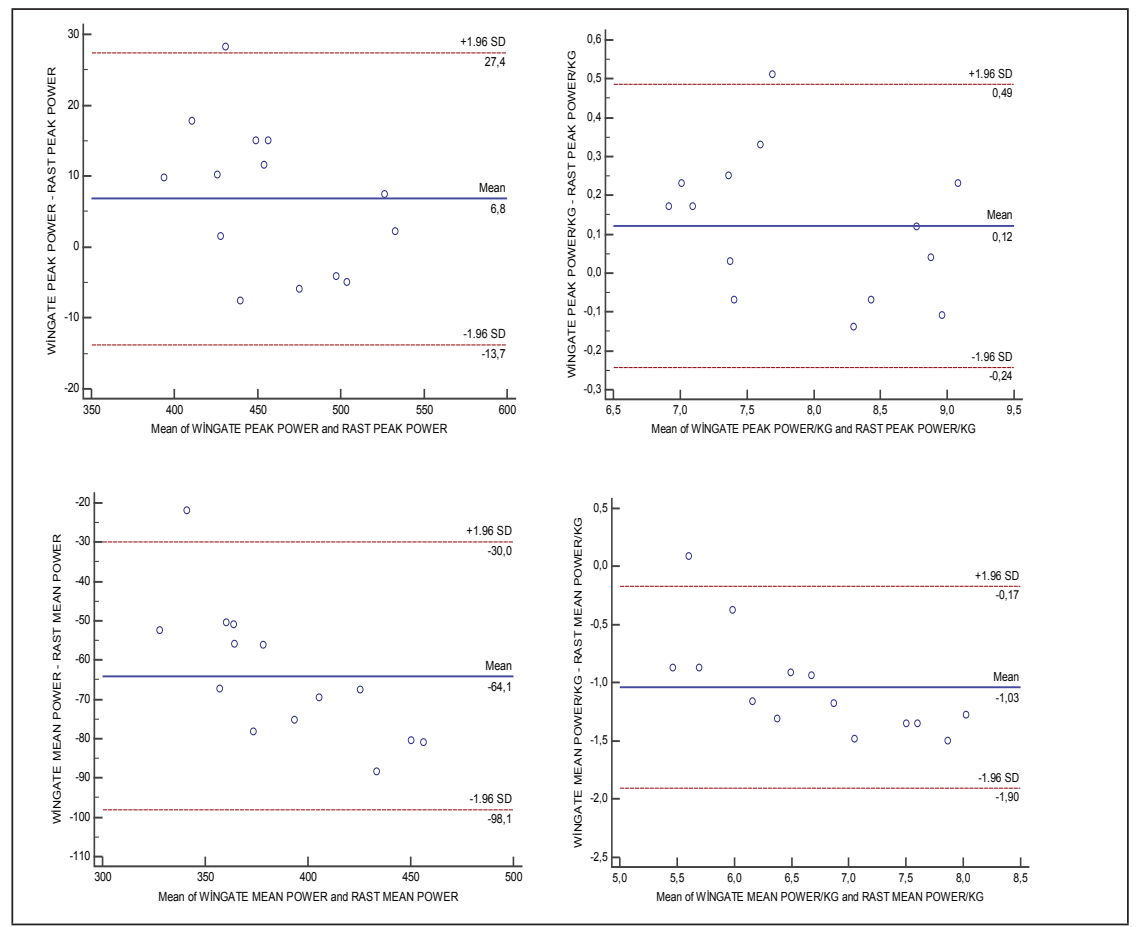

Grafik I. Wingate Testinden Elde Edilen Güç Değerleri ile 6×35 m Tekrarlı Sprint (RAST test) Testinden Elde Edilen Değerlerinin Farklarını Gösteren Bland Altman Grafikleri. 
Yapılan Multivariate Analysis of Variance (MANOVA) testi sonrası çalışmaya katılan sporcuların 6x35 m tekrarlı sprint (RAST test), 30 sn çoklu sıçrama ve wingate testinin hemen sonrası ve toparlanmanın 5.,7. ve 9. dakikası sonrası kalp atım hızları ve kan laktat değerleri arasında anlamlı farka rastlanmıştır.

Tablo 3. Kadın Futbolcuların Wingate, $6 \times 35$ m Tekrarlı Sprint (RAST test) ve 30 sn Çoklu Sıçrama Testi Sonrası Kalp Atım Hızı ve Kan Laktat Değerlerine Ait MANOVA Sonuçları

\begin{tabular}{|c|c|c|c|}
\hline & Anaerobik Testler & Ortalama \pm ss & F \\
\hline \multirow{3}{*}{ Dinlenik KAH } & RAST & $70,50 \pm 4,99$ & \multirow{3}{*}{0,446} \\
\hline & ÇOKLU SIÇRAMA & $69,21 \pm 5,47$ & \\
\hline & WINGATE & $68,57 \pm 6,00$ & \\
\hline \multirow{3}{*}{ Dinlenik Laktat } & RAST & $1,15 \pm 0,26$ & \multirow{3}{*}{0,908} \\
\hline & ÇOKLU SIÇRAMA & $1,26 \pm 0,19$ & \\
\hline & WINGATE & $1,23 \pm 0,24$ & \\
\hline \multirow{3}{*}{ Egzersiz Sonrası KAH } & RAST & $152,07 \pm 24,18$ & \multirow{3}{*}{$\begin{array}{c}20,18^{*} \\
(1-2 ; 2-3)\end{array}$} \\
\hline & ÇOKLU SIÇRAMA & $113,21 \pm 28,44$ & \\
\hline & WINGATE & $166,29 \pm 13,30$ & \\
\hline \multirow{3}{*}{ Egzersiz Sonrası Laktat } & RAST & $3,71 \pm 0,77$ & \multirow{3}{*}{$\begin{array}{c}3,62^{*} \\
(1-2 ; 2-3)\end{array}$} \\
\hline & ÇOKLU SIÇRAMA & $2,98 \pm 0,91$ & \\
\hline & WINGATE & $3,82 \pm 1,00$ & \\
\hline \multirow{3}{*}{$\begin{array}{c}\text { Egzersizin } 5 \text { Dakika } \\
\text { Sonrası KAH }\end{array}$} & RAST & $93,00 \pm 11,23$ & \multirow{3}{*}{$\begin{array}{c}18,66^{*} \\
(1-2 ; 2-3 ; 1-3)\end{array}$} \\
\hline & ÇOKLU SIÇRAMA & $78,64 \pm 7,48$ & \\
\hline & WINGATE & $112,43 \pm 21,57$ & \\
\hline \multirow{3}{*}{$\begin{array}{l}\text { Egzersizin } 5 \text { Dakika } \\
\text { Sonrası Laktat }\end{array}$} & RAST & $7,06 \pm 1,70$ & \multirow{3}{*}{$\begin{array}{c}17,07^{\star} \\
(1-2 ; 2-3)\end{array}$} \\
\hline & ÇOKLU SIÇRAMA & $4,34 \pm 1,34$ & \\
\hline & WINGATE & $8,06 \pm 2,10$ & \\
\hline \multirow{3}{*}{$\begin{array}{c}\text { Egzersizin } 7 \text { Dakika } \\
\text { Sonrası KAH }\end{array}$} & RAST & $88,86 \pm 8,28$ & \multirow{3}{*}{$\begin{array}{c}15,05^{*} \\
(1-3 ; 2-3)\end{array}$} \\
\hline & ÇOKLU SIÇRAMA & $81,64 \pm 10,84$ & \\
\hline & WINGATE & $103,71 \pm 12,94$ & \\
\hline \multirow{3}{*}{$\begin{array}{l}\text { Egzersizin } 7 \text { Dakika } \\
\text { Sonrası Laktat }\end{array}$} & RAST & $7,11 \pm 1,57$ & \multirow{3}{*}{$\begin{array}{c}18,41^{\star} \\
(1-2 ; 2-3)\end{array}$} \\
\hline & ÇOKLU SIÇRAMA & $4,42 \pm 1,21$ & \\
\hline & WINGATE & $8,12 \pm 2,10$ & \\
\hline \multirow{3}{*}{$\begin{array}{c}\text { Egzersizin } 9 \text { Dakika } \\
\text { Sonrası KAH }\end{array}$} & RAST & $84,93 \pm 8,63$ & \multirow{3}{*}{$\begin{array}{c}21,77^{\star} \\
(1-2 ; 1-3 ; 2-3)\end{array}$} \\
\hline & ÇOKLU SIÇRAMA & $77,5 \pm 8,67$ & \\
\hline & WINGATE & $98,64 \pm 8,50$ & \\
\hline \multirow{3}{*}{$\begin{array}{l}\text { Egzersizin } 9 \text { Dakika } \\
\text { Sonrası Laktat }\end{array}$} & RAST & $6,41 \pm 1,40$ & \multirow{3}{*}{$\begin{array}{c}17,01^{\star} \\
(1-2 ; 2-3)\end{array}$} \\
\hline & ÇOKLU SIÇRAMA & $3,79 \pm 1,25$ & \\
\hline & WINGATE & $7,21 \pm 2,10$ & \\
\hline
\end{tabular}




\section{TARTIŞMA}

Anaerobik yoldan iskelet kasının gücünü ve enerji üretim kapasitesini tahmin etmede değişik yöntemler geliştirilmiștir (Zagatto ve ark., 2009). Kullanılan bu yöntemlerden bazıları maksimum birikimli oksijen açı̆̆ı (MAOD) (Kaminagakura ve ark., 2012, Hill ve ark., 2002, Hoffman ve ark., 2002), wingate testi (WAnT) (Kaminagakura ve ark., 2012, Zagatto ve ark., 2009, Nummela ve ark., 2007, Beneke, ve ark, 2002, Bar-Or, 1987), maksimal anaerobik koşu testi (Queiroga ve ark., 2013, Nummela ve ark., 2007), margaria basamaklı koşu testi (Zagatto ve ark., 2009, Nedeljkovic ve ark., 2007), dikey sıçrama testi (Nummela ve ark., 2007, Sands ve ark., 2004, Bosco ve ar., 1983) ve diğer testlerdir. Ancak yaygın kullanılmalarına rağmen, bu yöntemler arasında anaerobik kapasiteyi ve gücü belirlemede altın standart olarak kabul edilen bir test henüz yoktur (Zagatto ve ark., 2009, Nummela ve ark., 2007, Sands ve ark., 2004). Bununla birlikte, anaerobik gücü ve kapasiteyi belirlemede maksimum birikimli oksijen açı̆̆ı ve wingate testleri bu kategorideki en iyi bilenen ve kabul edilen testlerdendir (Kaminagakura ve ark., 2012, Zagatto ve ark., 2009, Nummela ve ark., 2007, Hill ve ark., 2002, Hoffman ve ark., 2002, Beneke, ve ark, 2002, Scott ve ark., 1991, Bar-Or, 1987). Wingate testinden ölçülen parametrelerle anaerobik kapasite arasında bir ilişkinin olduğu değişik çalışmalarla da gösterilmiştir (Kaminagakura ve ark., 2012, Zagatto ve ark., 2009, Minahan ve ark., 2007, Hoffman ve ark., 2002). Bunun yanında, Wingate testinde anaerobik özelliklerin katkısının \% 55-87 arası düzeye ulaştığı ifade edilmiştir (Adamczyk, 2011, Spencer ve Gastin, 2001, Calbet ve ark., 1997). Beneke ve diğ. (2002) Wingate anaerobik testi süresince aerobik, anaerobik alaktik ve laktik asit metabolizmasının enerji katkılarının sırasıyla \%18.6, \%31.1 ve \%50.3 olduğunu ifade etmişlerdir. Wingate anaerobik testinde pik ve ortalama güç (anaerobik kapasite) için laktik asit metabolizmasından gelen enerji kaynaklarını ise sırasıyla $\% 83$ ve $\% 81$ olarak açıklamışlardır. Testi uygulayanların test sonrasında en yüksek laktat düzeyine sahip olması yüksek glikolitik kapasiteye veya anaerobik kapasiteye sahip oldukları anlamına gelebilir. Bunun sonucu olarak da wingate testinin sonrasında yüksek kan laktat değerlerinin elde edilmesi testin fizyolojik olarak anaerobik kapasiteyi yansıtması açısından geçerli olduğunu gösterebilmektedir. Wingate testi sonrasında elde ettiğimiz yüksek kan laktat değerleri bu sonuçları doğrular niteliktedir. Tekrarlanabilirliği ve kısa mesafeli sportif etkinliklerinde iyi bir performans belirleyicisi olması dolayısıyla wingate testi anaerobik gücün mükemmel bir öngörücüsü olarak gösterilmektedir (Zagatto ve ark., 2009). Anaerobik güç ve kapasitenin değerlendirilmesi için iyi bir yöntem olarak bilimsel kabul gördüğü için, wingate bisiklet testi farklı sportif özellikteki anaerobik değerlendirme testlerinin geçerliliğini doğrulamada standart yöntem olarak kullanılmaktadır (Queiroga ve ark., 2013, Zagatto ve ark., 2009, Almuzaini, 2000; Nummela ve ark., 1996, Tharp ve ark., 1985). Wingate testinde devreye giren kas gruplar1 tarafından mekanik güce karşılık gelen pik güç, ortalama güç ve yorgunluk indeksi gibi anaerobik güce dayalı veriler elde edilir (Bar-Or, 1996). Wingate testi avantajlı olmasına rağmen, kullanımı düzgün donanıma sahip laboratuarları gerektirir (Queiroga ve ark., 2013, Adamczyk, 2011). Bu yöntemler için cihazların satın alınması sınırlı olduğundan, anaerobik kapasiteyi belirlemek oldukça zor olur (Queiroga ve ark., 2013). Bununla birlikte araştırmacıların bir kısmı wingate testinin bisikletçilere daha özgü olduğunu ve bunun sonucunda branşa özgü anaerobik süreçleri belirlemede spor branşının yapısına uygun testlerin kullanımının daha uygun olabileceğini 
ifade etmişlerdir (Bakhtiari ve Rastegar, 2012, Kaminagakura ve ark., 2012, Changela ve Bhatt, 2012, Legaz-Arrese ve ark., 2011). Ancak bu tür testlerin anaerobik özellikleri yansıtması ve elde edilen güç değerlerine ait sonuçların güvenilirlik ve geçerliklerinin wingate testlerinden elde edilen değerlerle uyumu konusunda hala tartışma söz konusudur (Queiroga ve ark., 2013, Kaminagakura ve ark., 2012, Sands ve ark., 2004,).

Wingate testine benzer şekilde RAST testi, basketbol, hentbol, atletizmde $100 \mathrm{~m}, 200 \mathrm{~m}$ ve $400 \mathrm{~m}$ gibi yoğun ve ararlıklı ritim özelliği olan spor yapılarında anaerobik performansı değerlendirmede kullanılır (Queiroga ve ark., 2013, Adamczyk, 2011, Balciûnas ve ark., 2006, Paradisis ve ark., 2005). RAST testi, wingate testine benzer şekilde alt ektremitenin gücünü belirlemektedir, bununla birlikte RAST testi bisiklet yerine koşuyu kullanmakta ve eforun gücü bireysel vücut ağırlığı kullanılarak ölçülmektedir. Diğer branşlardaki sporlarda bu testin kullanımı maliyeti azalttığı ve uygulamasının kolaylığından dolayı oldukça ilgi çekicidir (Zagatto ve ark., 2009). Anaerobik bileşenler çeşitli sporlarda uygulananlara benzer şekilde tekrarlı sprintlerle değerlendirilmektedir (Kalva-Filho ve ark., 2013, Zagatto ve ark., 2009). RAST testi çeşitli sprint performansları ile yüksek korelasyon göstermesi dolayısıyla koşu performansını tahmin etmede iyi bir gösterge olarak görülmüştür (Zagatto ve ark., 2009). RAST testi ile wingate testi arasında yapılan çalışmalarda ise ilişki düzeyi konusunda çelişkili sonuçlar ortaya konmuştur (Queiroga ve ark., 2013, Bakhtiari ve Rastegar, 2012, Bakhtiari, 2012, Kaminagakura ve ark., 2012, Adamczyk, 2011, Zagatto ve ark., 2009). Bazı çalışmalarda iki test arasında güç parametreleri açısından anlamlı derecede yüksek ilişkiler tespit edilmiş, bunun sonucu olarak anaerobik güç ve kapasiteyi ölçmede RAST testinin kullanılabileceği ifade edilmiştir (Bakhtiari, 2012, Adamczyk, 2011, Zagatto ve ark., 2009). Bunun yanında, bazı çalışmalarda ise iki test arasında uyum düzeyinin zayıf olduğu ve iki testin birbiri yerine kullanılamayacağı ifade edilmiştir (Queiroga ve ark., 2013, Kaminagakura ve ark., 2012). Bir ölçüm tekniği ile referans olarak kullanılan ölçüm tekniğinin uyum düzeyi çeşitli istatistiksel yöntemler kullanılarak incelenir. Genellikle ölçüm teknikleri arasındaki uyum düzeyini belirlemek için korelasyon ve regresyon analizi kullanılmaktadır. Ancak, dağılım genişliği büyük olan örneklemlerde veya biri diğerinin katı olmasına rağmen yüksek ilişki gösteren örneklemlerde ilişki katsayısı yüksek olmasına rağmen uyum katsayısı zayıf olabilir. Bu yüzden iki yöntemin uyumunun araştırıldı̆̆ı çalışmalarda korelasyon ve regresyon analizleri yerine Bland-Altman tutarlılık ölçümlerinin kullanımının daha uygun olabileceği ifade edilmiştir (Genç ve ark., 2003). Çalışmamız sonucunda güç parametreleri açısından RAST testi ile wingate testi arasında yüksek korelasyon bulunmasına rağmen, BlandAltman tutarlılık gösteriminde iki ölçüm arasındaki farklılığın \%95 güven aralığını aştığı tespit edilmiştir (Grafik 1). Bunun sonucu olarak kadın futbolcularda RAST testinin anaerobik gücü ve kapasiteyi değerlendirmede wingate testinin yerine kullanılamayacağı sonucuna ulaşılmıştır. Benzer sonuçlar farklı spor gruplarıyla yapılan çeşitli çalışmalarda da desteklenmiştir (Queiroga ve ark., 2013, Kaminagakura ve ark., 2012).

Balistik devinim ve maksimal patlayıcı güç özelliği ortaya koyan dikey sıçrama hareketi güçplatform yöntemi kullanılarak belirlenebilir (Bosco ve ark., 1983). Yapılan çalışmamız sonucunda kadın futbolcularda çoklu sıçrama testi ile hem wingate hem de tekrarlı sprint testi arasında anlamlı olmayan düşük ilişkiler tespit edilmiştir. Dolayısıyla benzer şekilde kadın futbolcularda çoklu 
sıçrama testinin wingate testi yerine kullanılamayacağı sonucuna varılabilir. Fizyolojik özellikler de belirttiğimiz sonucu doğrulamaktadır. Hem kalp atım hızı hem de kan laktat değerleri açısından değerlendirildiğinde çoklu sıçrama testi wingate testine göre daha yüksek güç değerleri vermesine rağmen, egzersiz sonrası kalp atım hızı ve maksimal kan laktat değerleri açısından daha düşük sonuçlar ortaya koymaktadır. Fizyolojik değerlerin daha düşük çıkması kadın futbolcularda wingate testine oranla çoklu sıçrama testinin zorluk derecesinin daha düşük ve anaerobik katkı düzeyinin daha az olması anlamına gelmektedir. Birçok çalışmada sporcularda anaerobik güç performansının belirlenmesinde tekrarlı sıçrama testinin kullanımı değerlendirilmiştir (Bakhtiari, 2012, Sands ve ark., 2004, Bosco ve ark., 1983). Ancak, anaerobik gücün belirlenmesinde sıçrama testinin kullanımının bisiklet ergometresi testlerine göre sporun yapısına daha fazla özgü olduğu ifade edilmiştir (Bakhtiari ve Rastegar, 2012, Sands ve ark., 2004, Bosco ve ark., 1983). Bosco testinin uzama kısalma döngüsü tipi sporlarda daha cazip olduğu, bu tip aktivitelerde kullanımının daha iyi sonuç verebileceği ifade edilmiştir (Sands ve ark., 2004). Bacak aktivitesinin eşzamanlı kullanılıp kullanılmaması ya da üst vücut kaslarının aktif veya pasif olması durumu, üretilen güç değerlerinde oldukça önemli etkilere neden olabilmektedir (Changela ve Bhatt, 2012). Bu durum, farklı test protokollerinden alınan yanıtlar arasında bir tutarsızlık yaratarak istatistiksel korelasyon değerini küçültüyor olabilir (Bakhtiari ve Rastegar, 2012, Sands ve ark., 2004). Literatür incelediğinde ilişki düzeyindeki artış sporcu grubunun sıçrama konusunda antrene olma düzeyine göre değiştiği gösterilmiştir (Bakhtiari, 2012, Changela ve Bhatt, 2012, Bakhtiari ve Rastegar, 2012, Sands ve ark., 2004, Bosco ve ark., 1983). Sıçrama konusunda iyi antrene bireylerde sıçrama testleri wingate testi ile yüksek ilişkiler gösterilirken (Changela ve Bhatt, 2012, Bakhtiari ve Rastegar, 2012, Bosco ve ark., 1983), düşük antrene bireylerde düşük ilişkilerin olduğu gösterilmiștir (Nikolaidis ve ark., 2016, Sands ve ark., 2004). Bunun yanında, çalışmaların bir kısmı sıçrama testlerinin 20 yılı aşkın süredir anaerobik gücü değerlendirmede kullanılmasına rağmen, wingate testi kadar kabul düzeyine sahip olmadığını belirtmişlerdir (Saç ve Taşmektepligil, 2011, Harmon ve ark., 1991, Vandewalle ve ark., 1987). Güç değerleri açısından incelendiğinde literatürde çoklu sıçrama testinden elde güç değerlerinin wingate testinden daha yüksek olduğu gözlenmiştir (Harmancı ve ark., 2013, Sands ve ark., 2004, Bosco ve ark., 1983). Bu sonuçlar yaptığımız çalışma ile paralellik arz etmektedir. Yapılan araştırmalar sıçramada güç değerlerinin yüksek çıkmasının nedenini sıçrama sırasında daha fazla kas gruplarının devreye girmesiyle (iki bacağın eş zamanlı hareket etmesi ve üst vücut kaslarının da harekete dahil olması) ve havada kalış sırasında vücudun elastiki elemanlarında depolanan mekanik enerjinin daha büyük bir geri kazanımla (havada kalma sırasında depolanan potansiyel enerjinin kinetik enerjiye dönüşümü) devreye girmesiyle açıllamışlardır (Changela ve Bhatt, 2012, Bosco ve ark., 1983).

\section{SONUÇ}

Sonuç olarak, elde edilen korelasyon ve Bland-Altman tutarlılık gösterimine göre; kadın futbolcularda anaerobik performansı değerlendirmede kullanılan 3 farklı test yönteminin güvenirlik katsayılarının ve tutarlılıklarının birbirinden farklı olduğu ve anaerobik performansın farklı özelliklerini test ettikleri sonucuna varılmıştır. 


\section{KAYNAKLAR}

Adamczyk, J.G. (2011). The Estimation Of The Rast Test Usefulness In Monitoring The Anaerobic Capacity Of Sprinters In Athletics. Pol. J. Sport Tourism, 18, 214-218.

Almuzaini, K.S. (2000). Optimal Peak And Mean Power On The Wingate Test: Relationship With Sprint Ability, Vertical Jump And Standing Long Jump in Boys. Pediatric Exercise Science, 4, 349-359.

Bakhtiari, A. R., Rastegar, M. (2012). Correlation Between Running-Based Anaerobic Sprint Test (RAST) Field Tests, Sargent Jump And 300 Yard Shuttle Run Tests With Laboratory Anaerobic Wingate Test In Evaluation Of Indoor Soccer Player's Anaerobic Readiness. Annals of Biological Research, 3(1), 377-384.

Balciunas, M., Stonkus, S., Abrantes, C., Sampaio, J. (2006). Long TermEffects Of Different Training Modalities On Power, Speed, Skill And Anaerobic Capacity In Young Male Basketball Players. J Sports Sci Med., 5, 163-170.

Baljinder, S., Ashok, K., Ranga, M.D. (2014). Comparison of Vertical Jump Performance of Male Handball \& Basketball Players. Journal of Exercise Science and Physiotherapy, 10(1), 64-68.

Bar-Or, O. (1987). The Wingate Anaerobic Test: An Update On Methodology, Reliability, And Validity. Sports Med., 4,381-394.

Bar-Or, O. (1996). Anaerobic Performance. In: Measurement in Pediatric Exercise Science. D. Docherty, ed. Champaign, IL: Human Kinetics, 161-182.

Beneke, R., Pollmann, C., Bleif, I., Leithauser, R. M., Hutker, M. (2002). How Anaerobic İs The Wingate Anaerobic Test For Humans?. European Journal of Applied Physiology, 87, 388-392.

Bosco, C. Luhtanen, P. Komi, P.V. (1983). Simple Method for Measurement of Mechanical Power in Jumping. Eur J Appl Physiol, 50, 273-282.

Calbet, J.A.L., Chavarren J., Dorato C. (1997). Fractional Use Of Aerobic Capacity During A 30 And 45-S Wingate Test. Eur. J. Appl. Physiol. 76, 308-313.

Changela, P.K., Bhatt, S. (2012). The Correlational Study of The Vertical Jump Test and Wingate Cycle Test As a Method to Assess Anaerobic Power in High School Basketball Players. International Journal of Scientific and Research Publications, 2(6), 1-6.

Genç, Y., Sertkaya, D., Demirtaş, S. (2003). Klinik Araştırmalarda İki Ölçüm Tekniğinin Uyumunu İncelemede Kullanılan İstatistiksel Yöntemler. Ankara Üniversitesi Tip Fakültesi Mecmuası,56(1), $1-6$.

Green, S., Dawson, B.T. (1995). The Oxygen Uptake-Power Regression İn Cyclists And Untrained Men: Implications For The Accumulated Oxygen Deficit. Eur J Appl Physiol., 70:351-359.

Harmancı, H., Kalkavan, A., Karavelioğlu, M.B., Şentürk, A. (2013). Effects Of Creatine Supplementation On Motor Performance İn Female Futsal Players. The Online Journal of Recreation and Sport, 2(4), 14-20.

Harmon, E.A., Rosenstein, M.T., Frykman, P.N., Rosenstein, R.M., Kraemer, W.J. (1991). Estimation Of Human Power Output From Vertical Jump. J. Appl. Sport Sci. Res, 5, 116-120.

Hill, D.W., Davey, K.M., Stevens, E.C. (2002). Maximal Accumulated $\mathrm{O}_{2}$ Deficit in Running And Cycling. Can J Appl Physiol, 27, 463-478.

Hoffman, J.R., Maresh, C.M., Newton, R.U., Hoffman J.R., Maresh, C.M., Newton, R.U., Rubin, M.R., French, D.N., Volek, J.S., Sutherland, J., Robertson, M., Gómez, A.L., Ratamess, N.A., Kang, J., Kraemer, W.J. (2002). Performance, Biochemical, And Endocrine Changes During A Competitive Football Game. Med Sci Sports Exerc., 34(11), 1845-53.

Jastrzebski, Z. (1995). Selected Aspects Of The Assessment Of Anaerobic Capacity By Applying The Wingate Test. Biol. Sport, 12,131-135. 
Kalva-Filho, C.A., Loures, J.P., Franco, V.H., Kaminagakura, E.I., Zagatto, A.M., Papoti, M. (2013). Comparison Of The Anaerobic Power Measured By The Rast Test At Different Footwear And Surfaces Conditions. Rev Bras Med Esporte, 19(2), 139-142.

Kaminagakura, E.I., Zagatto, A.M., Redkva, P.E., Gomes, E.B., Loures, J.P., Kalva-Filho, C.A., Papoti, M. (2012). Can the Running-Based Anaerobic Sprint Test be used to Predict Anaerobic Capacity?. Journal of Exercise Physiologyonline, 90-99.

Legaz-Arrese, A., Munguía-Izquierdo, D., Carranza-García, L.E., Torres-Dávila, C.G. (2011). Validity Of The Wingate Anaerobic Test For The Evaluation Of Elite Runners. J Strength Cond Res., 25, 819-824.

Meckel, Y., Atterbom, H., Grodjinovsky, A., Ben-sira, D., Rotstein, A. (1995). Physiological Characteristics Of Female 100 Metre Sprinters Of Different Performance Levels. J Sports Med Phys Fitness, 35, 169175.

Minahan C., Chia, M., Inbar, O. (2007). Does Power İndicate Capacity? 30-S Wingate Anaerobic Test Vs. Maximal Accumulated $\mathrm{O}_{2}$ Deficit. Int J Sports Med., 28, 836-843.

Nedeljkovic, A., Mirkov, D.M., Pazin, N., Jaric, S. (2007). Evaluation Of Margaria Staircase Test: The Effect Of Body Size. Eur J Appl Physiol, 100, 115-120.

Nikolaidis, P.T., Afonso J., Vicente Javier Clemente-Suarez, Alvarado, J.R.P., Driss T., Knechtle B., Gema Torres-Luque (2016). Vertical Jumping Tests Versus Wingate Anaerobic Test In Female Volleyball Players. The Role of Age Sports, 4(9), 2-7.

Nummela, A., Alberts, M., Rijntjes, R.P., Luhtanen P., Rusko, H. (1996). Reliability And Validity Of The Maximal Anaerobic Running Test. Int. J. Sports Med. 17(Suppl 2), 97-102.

Nummela, A., Hämäläinen, I., Rusko, H. (2007). Comparison Of Maximal Anaerobic Running Tests On A Treadmill and Track. J Sports Sci., 25, 87-96.

Paradisis, G.P., Tziortzis, S., Zacharogiannis, E., Smirniotou, A., Karatzanos, L. (2005). Correlation Of The Running-Based Anaerobic Sprint Test (RAST) And Performance On The 100m, 200m And 400m Distance Tests. nJournal of Human Movement Studies, 49, 77-92.

Reiser, R. F., Rocheford, E. C., Armstrong, C. J. (2006). Building A Better Understanding Of Basic Mechanical Principles Through Analysis Of The Vertical Jump. Strength and Conditioning Journal, 28(4), 70-80.

Saç, A., Taşmektepligil, M.Y. (2011). Farklı Sporcu Gruplarında Üç Ayrı Anaerobik Güç Ölçüm Yöntemiyle Elde Edilen Sonuçların Değerlendirilmesi. Spor ve Performans Araştırmaları Dergisi, 2(1),

Sands, W.A., McNeal, J.R., Ochi, M.T., Urbanek, T.L., Jemni, M., Stone M.H. (2004). Comparison Of The Wingate And Bosco Anaerobic Test. Journal of Strenght and Conditioning Research, 18(4), 810-815.

Scott, C.B., Roby, F.B., Lohman, T.G., Bunt, J.C. (1991). The Maximally Accumulated Oxygen Deficit As An Indicator Of Anaerobic Capacity. Med Sci Sports Exercise, 23, 618-624.

Semler, C.C. (2011). Effect Of Plyometric Training And Squats On The Vertical Jump Performance Of Untrained Females, In Health and Sport Science Dissertation, The University of Memphis.

Smith, J.C., Hill, D.W. (1991). Contribution Of Energy Systems During A Wingate Power Test. Br J Sport Med., 25, 196-199.

Spencer, M.R., Gastin, P.B. (2001). Energy System Contribution During 200 To 1500 m Running In Highly Trained Athletes. Med Sci Sports Exerc., 33, 157-162.

Tharp, G., Newhouse, R., Uffelman, L., Thorland, W., Johnson, G. (1985). Comparison Of Sprint And Run Times With Performance On The Wingate Anaerobic Test. Res. Q Exerc Sport, 56, 73-76.

Querioga, M.R., Cavazzotto, T.G., Katayama, K.Y., Tartaruga, M.P., Ferreira, S.A. (2013). Validity Of The Rast For Evaluating Anaerobic Power Performance As Compared To Wingate Test In Cycling Athletes. Motriz, Rio Claro, 19(4), 696-702. 
Vandewalle, H., Peres, G., Monod, H. (1987). Standard Anaerobic Exercise Tests. Sports Med., 4(4), 268-89.

Zacharogiannis, E., Paradisis, G., Tziortzis, S. (2004). An Evaluation Of Tests Of Anaerobic Power And Capacity. Med Sci Sports Exerc., 36, 116.

Zagatto, A.M., Beck, W.R., Gobatto, C.A. (2009). Validity Of The Running Anaerobic Sprint Test For Assessing Anaerobic Power And Predicting Short-Distance Performances. Journal of Strength and Conditioning Research, 23(6), 1820-1827.

Zagatto, A.M., Redkva, P., Loures, J., Kalva, F.C., Franco, V., Kaminagakura, E., Papoti, M. (2011). Anaerobic Contribution During Maximal Anaerobic Running Test: Correlation With Maximal Accumulated Oxygen Deficit. Scand J Med Sci Sports., 1, 1-9. 